Journal of

APF Command and Staff College

\title{
Intelligence in the National Security Enterprise: An Introduction Roger Z. George
}

Washington DC, United States: Georgetown University Press. February 2020. Pp. xvii+328. US\$ 153.38. ISBN10: 1626167435 \& ISBN 13: 9781626167438

Article History

Received September 4, 2020

Accepted October 21, 2020

Intelligence is one of the major aspects of national security decision-making. The last 50 years witnessed a significant growth of intelligence agencies. The United States of America has the largest and most complex intelligence system in the world. At present, the US intelligence system employs more than one hundred thousand people in sixteen intelligence agencies and spends more than USD 70 billion annually. The rumors and failures in its activities, i.e. illegal domestic spying, controversial covert action, a shock of terrorist attack, a faulty prediction of weapons of mass destruction dragged the US intelligence mission in controversy in the homeland and overseas. The underlying questions, i.e. why intelligence fails? Who is responsible for intelligence failure and its consequences? What is the relationship between the Intelligence Community and policy decision makers? are matters for strategic intervention are serious concerns and interests for strategic, political and academic communities across the world. In this background, the book 'Intelligence in the National Security Enterprise: An Introduction' by Roger Z. George, a former CIA analyst, and professor of intelligence and national security offers a descriptive and analytical view towards the critical role of the US intelligence community within the wider national security decision-making and political process.

The book provides a clear explanation of the expanding US national security enterprise (NSE), in which intelligence operates and distinguishes among a range of intelligence functions that contribute to the National Security Enterprise. Moreover, the book enables an in-depth analysis of how intelligence serves the policymakers. With a brief description of what intelligence is and what intelligence agencies do, a three hundred forty-four-page book is divided into eleven chapters and each chapter begins with relevant quotes on intelligence that captures readers to continue concentration throughout the contents of the specific chapter.

The first chapter 'how to use the book' explains the overall outline of the book. It is dedicated to the scope of intelligence in the United States and across the world. The beginning quote 'keep giving me things that make me think' by Henry Kissinger to Richard Helms, Central Intelligence Agency (CIA) director, awakens readers to critically contemplate on what information is required for a strategic thinker (Page, 1). Kissinger's 
single line statement clarifies a symbiotic relationship between intelligence and policy communities analyzing how the US national security policy is conducted through in a more detailed description of how intelligence contributes to the development of such policies.

Indicating the role of intelligence in US National security decision making, chapter two primarily deals on 'what is Intelligence' and elaborates major terminologies connected to intelligence collection, types, and analysis. The use of three intelligence disciplines, technical intelligence (TECHINT) and human intelligence (HUMINT), and open-source intelligence (OSINT) is taken as main source classified and unclassified information for analysts to detect significant international security developments. Further, the intelligence cycle is emphasized in a stepwise sequence of intelligence work from the collection, processing, analysis, evaluation, dissemination, and policy consumption. The institutionalization of intelligence support to senior policymakers in the United States is regarded as a major contribution of The National Security Act of 1947 that made an understandable provision of expansion of national security council beyond the president's diplomatic and military advisers to include the Director of Central Intelligence (DCI) as president's key intelligence adviser.

The article (2) of the US constitution has given full authority to the president for unparalleled control over national security. The main emphasis of third chapter is 'National Security Enterprise' and chapter unlocks discussion around the way of national security policy is made in the United States and how intelligence fits into that decision making process with the historical background of establishment of the national security structures i.e. Joint Chiefs of Staff, National Security Advisor, State Department, Department of Defense, Federal Bureau of Investigation (FBI), Department of Homeland Security (DHS), Treasury Department, Commerce Department, Economic Department. In addition, the evolution of the national security system over the past half-century and establishment of various mechanisms of intelligence during the tenure of various presidents were also discussed. With attention-grabbing the role of the National Security advisor is presented and the author locates the role of position as 'an advocate vs. honest broker'(Page 41).

Chapter four discusses 'Intelligence Community' with an ample description. Discussing eight DoD and eight non-DoD members of the Intelligence community, the author in this chapter highlights the various types of information and role of every intelligence agency in terms of providing the best available information to the nation's senior civilians and military decision-makers (Page 52). In addition, with detailed explanation of the Intelligence Community, the author gives a reasonable explanation of why and how Director of National Intelligence (DNI) became central position with the intelligence reform and terrorism prevention Act of 2004 in the aftermath of September 11, 2001 terrorists' attacks.

With detailed illustration and explanation of the intelligence cycle (page 84), chapter five - 'Intelligence Cycle Policy Support' - postulates insights on theoretical and practical aspects of intelligence work. It clearly illustrates the 'cyclic relationship' among 
the collectors, analysts, and policymakers in the intelligence system (page, 86). Also, intelligence collection constraints, analysts' priority, and precision in policy decisions discussed with various past events. Placed at the center of the cycle, analysts' role is taken very critical to create proper meaning through raw data collected by various intelligence agencies across the world.

Chapter six deals explicitly on the role of 'strategic intelligence' in the US Mission along with its collection and analysis process. Categorizing the level of intelligence, the author outlines three types of intelligence, i.e. basic, current and strategic (Page, 112). Out of these three categories, strategic intelligence is labeled as high-priority and the result of longer-term dynamic assessment of the international political and security environment and geostrategic priority for the country. Also, the author indicates a great shift on strategic issues from the period of cold war to present days and discuss the challenges faced by policy makers and National Intelligence Council (NIC). The challenges with modern security trends or factors that alter the international conditions in which the United States policy makers must operate also given great emphasis. National Intelligence Estimates (NIES) process and products is the central charm of the chapter. It imparts knowledge on how the publication of unclassified strategic assessment by NIC becomes helpful to senior US leaders to think main trends and uncertainties might shape the world over the next 20 years as well as to plan for US longer term intelligence priorities. The examples of various global trend reports over the different periods of time (1997, 2001, 2004, 2008, 2012, and 2017) make the chapter more stimulating to readers. The example of the failure case of NIE in Iraq's Weapon of Mass Destruction (WMD) program in 2002 helps readers to believe to what extent strategic intelligence is relevant and how it impacts on overall policy making in detail.

Chapter seven is focused on 'challenges of warnings' and begins with former CIA director John McCone's quote 'successful warning is essentially a two-fold process; if warning is to be effective, not only must the alert be given, but the consumer of intelligence must accept the fact that he has in fact been warned' (page, 145). In line with the quote, chapter deliberates on the concept of warning, including how it conducted and organized along with a strong emphasis on the Intelligence Community's enduring responsibility to provide warning of threats to the United States and its interests abroad. What characteristics qualify strategic warning, how it is different from tactical warning and philosophy of warning intoxicate readers to follow the chapter thoroughly. A brief examination of cases Japanese attack on Pearl Harbor in 1941, North Korean invasion of South Korea in 1950, Cuban missile crisis of 1962, Israeli six-days war against Arab States in 1967, Egyptian attack on Israel in 1973, Soviet invasion of Afghanistan of 1979, Iraqi invasion of Kuwait in 1990, Breakup of the Soviet Union and Yugoslavia and Al-Qaeda attack in 2001 are used to identify lessons to be learned from past warning cases. The overall discussion of various cases helps readers to understand successes and failures of warning in great details. Even in the situation where policymakers are warned, sometimes surprise happens in the real world, which is perfectly reviewed. The chapter concludes with an examination of how the warning function has been organized in the US in the past and how recent practices have been shifting the burden of warning from specialized warning staff to every analyst. 
Invisible mission of direct policy support provided to virtually every major national security agency in the US government is chapter eight 'Intelligence Support as Policy Enabler'. Author illustrates how intelligence supports policymakers with information and analysis relevant to their decisions without intending to favor or oppose them. The precise understanding of the President's Daily Brief (PDB) and the process behind it is a unique feature of this chapter. It also describes specialized types of intelligence support to policymakers engaged in ongoing international negotiations, crisis management, and counter terrorism efforts.

The primary focus of chapter nine is on the special and controversial intelligence mission of 'covert action as policy support', acknowledged as 'a policy instrument'. It further discusses how covert actions are authorized and monitored by both the executive and legislative branches and what makes covert action success and failure. Review of covert action, using historical as well as more recent operations-1953 Coup in Iran, the 1961 Bay of Pigs Fiasco, the 1986 Iran-Contra Operation, US covert mission in Afghanistan from 1980-88 - to illustrate the benefits, costs, and risks of such activities make chapter interesting. Also, the chapter makes readers realize how national security policy and intelligence are even more linked and less distinct than usual.

Chapter Ten 'Challenges of Intelligence-Policy relationship' discusses various tests and trials of the intelligence and policy nexus. Roger offers a strong indication of critical and repeated difficult relationships between intelligence and policy making process in the US's experience. The risks of "politicization" of intelligence have been discussed thoroughly. The Bush administration's manipulation and misuse of intelligence during the war in Iraq and the tussle experienced between intelligence and leadership has been publicized as an example.

The last and concluding chapter 'Intelligence and American Democracy' reveals an uneasy belief between the intelligence community and ordinary citizens, termed as 'controversial and problematic' (page, 265). An adequate description and analysis of executive, legislative, and judicial oversight mechanism within the framework of US Constitution and federal law where the writer examines challenges and catastrophes experienced in selective cases i.e. Vietnam War protests of the 1960s and 1970s and intelligence abuse or violation on Americans' civil liberties that occurred during the Nixon administration. demonstrating various cases of the violation of democratic principles in its efforts as well as pose the challenge to safeguard national security, chapter offers clear understanding on the discourse of privacy and security evolving in the United states from the cold war era to modern days. Also, the author talks about some of the legal provisions and oversights the practice of intelligence. The major legal provisions-United States National Security Act of 1947, Central Intelligence Agency Act of 1949, Intelligence Oversight Act of 1980, Foreign Intelligence Surveillance Act (FISA) of 1978 etc.-clearly indicate the FBI's legal compliance with law-enforcement methods for intelligence collection within the US territory. However, the CIA and other foreign intelligence agencies are free to use less savory and top-secret collection methods overseas. Shortening on-going debate and the dilemma of balancing security and protecting citizens' privacy under the American Democracy, Roger concludes the volume. 
The book undoubtedly touches on the evolution of each intelligence agency and the responsibility of these organizations. The most fascinating aspect of the book is the author's in-depth explanation of NSE with a detailed description of the intelligence community and the range of intelligence functions that contribute to the top civil and military leadership of the United States. It is no doubt, the microscopic analysis of various incidents of intelligence failure indicates the author's thirty-year CIA expertise and more than a decade of teaching experiences. The theoretical and practical combination is helpful for the readers to understand the 'overt and covert' reality of intelligence. Apart from the use of complex disciplinary jargon and the repetition of the various examples across the different chapters for different understanding purposes, the book is well organized and clearly written. It has a sufficient number of excerpts, figures to assist the reader in navigating the diverse concepts and cases presented. Furthermore, a glossary at the end of the book and links to primary-source documents and suggestions for further readings following each chapter allows the readers to explore a given topic to a greater depth than would a cumulative bibliography. Thus, the volume succeeds in advancing a call for a more practical approach to strengthening the relationship between intelligence and policy community as well as inter-agency coordination and collaboration among existing sixteen intelligence agencies.

The balance insights on overall concepts; what intelligence is and what the intelligence community does, what is the relationship between intelligence and policy community, along with the detailed examination of the existing intelligence support system of the United States make this book very relevant to policy and practitioners. The book is completely US-centric. In order to learn in- depth insights of the intelligence empire across the world, it is a gateway but not the perfect solution for the rest of the world. Examples and cases discussed throughout the book are also based on intelligence missions carried out by Intelligence agencies within and outside of the United States. To some aspect, that is challenging and less concerning to non-American readers. The book itself is a result of the author's preoccupied thinking of security enterprise in the US and it demands basic knowledge of US political history on readers as foundation to digest this book perfectly. Non-American readers and people with limited understanding of the security field can criticize the author for two main reasons. First, the use of complex disciplinary jargon throughout the book. Second, the repetition of a few examples across the different chapters for making clarity on intelligence cycle different purposes.

The comprehensive understanding of the complex Intelligence system is almost impossible. However, the reviewer has succeeded to build a fair understanding of US national security enterprise and intelligence community work in policy cycle. In the eyes of the reviewer, 'the book' offers academic and real world insights-both in theory and practice of the US' intelligence community and their work across the world, which is rarely observed in other volumes of national security. Being a former CIA analyst, the author is ideally balancing transparency and privacy of overseas covert action in the book. At the same time, the author maintained the United States' national interest first and he equally does justice for overseas readers by providing clear insights of intelligence failure in various US missions. As an honest admission, the author completes the factors affecting US intelligence failures abroad as failure of Intelligence Community to 
predict events timely, failure of policy community to notice intelligence warnings adequately and communication gap between intelligence officers and policy officials. This book educates readers on the role of each and every individual in the intelligence cycle. By and large, intelligence is not only a matter of the politico-military realm. Beyond the framework of national security and foreign policy, the scope of intelligence is broad and taken as an effective measure of domestic policy and human security. Despite publishing this book in the form of a textbook for security students, the book is advantageous to civilians, military, and policymakers interested in intelligence and national security across the world. In the context of Nepal, the reviewer realized this book is valuable for faculties and graduate level students of security, international relations and conflict studies programs. Apart from teaching and learning purposes, the book is equally beneficial for and Nepalese strategic thinkers, military and other law enforcement agencies officers, intelligence community members, and top-brass policymakers to re-think, realize and improve neglected and less-prioritized intelligence systems of Nepal.

Chiranjibi Bhandari Assistant Professor Department of Conflict, Peace and Development Studies; T.U.

\section{References}

Andrew, Christopher., Aldrich, Richard J. and Wark, Wesley K. (2020). Secret Intelligence: A Reader (2nd Edition). London: Routledge printed by Taylor and Francis Group.

Clark, John Ransom (2007). Intelligence and National Security: A Reference Handbook. United States: Praeger Publishers

Finger, Thomas (2011). Reducing Uncertainty: Intelligence Analysis and National Security. United States: Stanford Security Studies. 